\title{
HABILIDADES COGNITIVAS DE UM ADOLESCENTE COM ANARTRIA E TETRAPLESIA
}

\author{
CELINA MARIA RAMOS A. MACEDO \\ (Universidade Federal de Santa Catarina)
}

\begin{abstract}
T H$ is tetraplegic and speech impaired. Although some studies show brain impairment among speech impaired could be associated with a decrease in the intellectual level, the findings of the experiments show that he has a cognitive performance in many aspects very similar to the control group. This study stresses, particularly, the way TH represents the graphic material, how he puts together objects and events within categories, how he accomplishes deductive and inductive reasoning, how he makes inferences about the mental state of other people and how he stores in memory information received minutes earlier.
\end{abstract}

Key-words: Tetraplegic, anarthria, cognitive processes.

\section{INTRODUÇÃO}

Este artigo tem por finalidade estudar o caso TH, sujeito que nasceu em 05/06/85, de parto com fórceps, e sofre uma anoxia que lhe causou seqüelas motoras graves - tetraplesia. TH também é anártrico, ou seja, apresenta a impossibilidade de articular palavras, embora não haja paralisia dos músculos da fonação. Todavia, TH cursava a sétima série do ensino fundamental de uma escola pública experimental de Florianópolis. Atualmente, TH cursa agronomia na Universidade Federal de Santa Catarina.

Nesta pesquisa experimental, decidiu-se trabalhar com o sujeito TH em razão de que estudos demonstram que o comprometimento cerebral entre pessoas não falantes poderia estar associado à diminuição do nível intelectual (BISHOP \& ROBSON 1989; EDEBOLTYSK, 1989). Além disso, Bishop e Robson (1989) afirmam que crianças anártricas apresentam uma clara inferioridade na escrita de palavras e de pseudopalavras, quando comparadas a crianças com enfermidade motora, mas sem problemas na fala. Apesar de que algumas pessoas não falantes aprenderem a ler, algumas pesquisas evidenciam as dificuldades que essas crianças, com paralisia cerebral, demonstraram quando adquiriam habilidades de letramento (BERNINGER \& GANS 1986A, B; BISHOP \& ROBSON, 1989; FOLEY, 1993; KELFORD SMITH, THURSTON, LIGHT, PARNES \& O' KEEFE, 1989; KOPPENHAVER, EVANS \& YODER, 1991; MCGINNIS \& BEUKELMAN, 1989; SMITH, M.M., 1989). Contudo, contrariando estes estudos, Macedo C., (no prelo), no artigo "Leitura e escrita na ausência da fala" sugere que o sujeito TH apresente as habilidades de compreensão oral, leitura e escrita com desempenho normal frente ao grupo controle colegas de sala de aula. 
MACEDO - Habilidades cognitivas de um adolescente...

Já que TH apresenta as habilidades de compreensão oral, leitura e escrita, parece oportuno observar e examinar os processos do pensamento, utilizado por TH em situações que implicam raciocínio, atribuição de crença e de inferências, categorização, análise de material gráfico e memória imediata. Portanto, esta pesquisa experimental tem em mira vários tipos de processos cognitivos e seu desenvolvimento. Ou seja: este artigo pretende tratar do modo pelo qual TH, sujeito tetraplégico e anártrico, percebe, aprende, recorda e pensa sobre uma dada informação.

Nesta pesquisa há seis experimentos, a saber: teste de inteligência geral - matriz de Raven (1938); categorização - teste de emparelhamento espontâneo de imagens; teste de raciocínio - tarefa de seleção de Wason (1966); memória de curto prazo - tarefa de dígito de sondagem escopo (digit probe-span); teoria da mente - tarefa de falsa crença, tarefa de falsa crença de segunda ordem e tarefa de faux pas; e o teste de cognição visual de Palmer (1977; cf também KOLINSKY, MORAIS \& MENDES, C.B. 1990; KOLINSKY, MORAIS, CONTENT \& CARY, 1987). Fez parte, também, destes experimentos a anamnese.

O objetivo geral destes seis experimentos é o de investigar e caracterizar os processos cognitivos de TH. O estudo enfatiza, especialmente, o modo pelo qual TH representa um material gráfico, como agrupa objetos e eventos em categorias, como realiza um raciocínio dedutivo e/ou indutivo, como faz inferência sobre os estados mentais de outras pessoas e como mantém na memória informações recebidas alguns segundos antes.

Considerando que TH teve um desempenho normal nas habilidades de letramento, Macedo, C., (no prelo), a hipótese a ser testada, neste estudo, é a de que o sujeito TH tem um desempenho cognitivo normal; a hipótese alternativa que ele apresentaria deficiências cognitivas nos domínios investigados. Com esse objetivo, a performance de TH será comparada tanto com o escore médio quanto com o escore inferior, observado no grupo de sujeitos controles, ou seja, de seus colegas de sala de aula.

\section{PRESSUPOSTOS TEÓRICOS}

A criança com paralisia cerebral tem dificuldade em controlar a sua postura e seus movimentos, como consequiência de uma lesão cerebral. Algumas crianças têm perturbações ligeiras, quase imperceptíveis, que as tornam desajeitadas para andar, falar ou para usar as mãos. Outras são afetadas com incapacidade motora grave, impossibilidade de andar e falar, sendo dependentes nas atividades da vida diária, sendo este o caso de $\mathrm{TH}$.

A paralisia cerebral é uma disfunção neurológica que atinge tanto a função motora grossa quanto a fina (SANDBERG e HJELMQUIST, 1997). Indivíduos com problemas motores graves sofrem de anartria, uma ausência completa da fala. Apesar de TH não emitir palavras, emite sons: gritos e gargalhadas.

De acordo com (BISHOP \& ROBSON, 1989 e EDEBOL-TYSK, 1989) o comprometimento cerebral entre pessoas não falantes poderia ser associado com diminuição de nível intelectual. Esse atraso intelectual, não só é devido às lesões cerebrais, mas também devido à falta de experiência. Corroborando com essa idéia, Dahlgren Sandeberg \& Hjelmquist (1996) afirmam que o dano motor limita o contato dessas crianças com o mundo a sua volta, o que causa um conhecimento de vocabulário limitado. 
Cadernos de Estudos Lingüísticos 48(2) - Jul./Dez. 2006

De acordo com Bishop e Adams (1990), a competência lingüística e a habilidade de linguagem são relacionadas à habilidade de letramento na população falante. Há vários estudos sobre as habilidades lingüísticas entre crianças anártricas e disártricas com paralisia cerebral (BISHOP, 1985, BISHOP \& ROBSON, 1989; BISHOP et al., 1990). Esses estudos demonstraram que as habilidades de soletração de sujeitos não falantes estavam abaixo do nível dos sujeitos controles.

Existem indicações na literatura que crianças não falantes têm problemas com a representação de sons das palavras na memória, (SANDBERG D.A., \& HJELMQUIST, 1996). Essa dificuldade com a representação de sons das palavras na memória poderia apresentar problemas para a construção de uma representação estável na memória (GATHERCOLE \& BADDELEY, 1990).

Pesquisadores neuropsicológos têm encontrado que o sistema funcional sustenta a memória viso-espacial de curto prazo. Estes pesquisadores têm indicado que os danos neurológicos encontrados na região parietal do hemisfério direito resultam em indícios de déficits na performance da memória visual enquanto a habilidade de memória verbal permanece intacta (FARAH, 1988; FARAH, HAMOND, LEVINE, \& CALVANIO, 1988; HANLEY, YOUNG, \& PEARSON, 1991). Correspondentemente, enquanto os danos na área de Broca estão associados com específicos déficits na memória de curto prazo as funções de memória viso-espacial permanecem normais. Estes achados fortalecem a visão de que a performance da memória de curto prazo, viso-espacial e fonológica são medidas por sistemas de memória funcionalmente separados (GATHERCOLE \& BADDELEY, 1990).

Vários estudos têm relatado uma correlação entre linguagem e performance na tarefa de teoria da mente (CUTTING \& DUNN, IN PRESS; HUGHES \& DUNN, 1977). Bretherton, McNew e Beeghly-Smith (1981) argumentam que a teoria da mente se desenvolve entre o primeiro e o quinto ano de idade, portanto em um período importante para a aquisição de linguagem, o que leva a Gopnik (1990) a fazer uma relação entre teoria da mente e aquisição de linguagem. Crianças autistas que, geralmente, fracassam na tarefa de teoria da mente, são atrasadas no desenvolvimento da linguagem e apresentam padrões de performance lingüísticos diferentes das crianças que não sofrem de autismo (TAGERFLUSBERG, 1993). Portanto, segundo Astington \& Jenkins (1981), o desenvolvimento da linguagem precede e promove o desenvolvimento da teoria da mente.

A matriz de Raven é, freqüentemente, usada em estudos sobre crianças não falantes por ser considerada um teste fácil de ser administrado nesse tipo de população (BADDELEY \& WILSON, 1985; BISHOP \& ROBSON, 1989; HJELMQUIST 1989). No estudo de Dahlgren Sandeberg \& Hjelmquist (1996) crianças não-falantes com paralisia cerebral e crianças falantes foram comparados o QI e idade mental combinado. A partir das análises dos resultados, observou-se que algumas crianças não falantes tinham a habilidade de letramento. Para identificar importantes fatores deste processo de comparação, os teste, também, foram aplicados em crianças não falantes que não tinham demonstrado as habilidades de leitura e soletração. Os baixos resultados nos testes de leitura e soletração das crianças não falantes não foram relacionados com baixo nível intelectual. 
MACEDO - Habilidades cognitivas de um adolescente...

Sobre indivíduos não falantes com paralisia cerebral, encontrou-se uma extensa literatura sobre as habilidades de leitura e escrita. Ao contrário, pouca literatura sobre os processos cognitivos estudados, nesta pesquisa, foi encontrada.

\section{O SUJEITO TH}

TH nasceu em $05 / 06 / 85$, por parto induzido que lhe causou seqüelas motoras graves, inclusive o comprometimento na fala.

Desde o nascimento, TH recebe acompanhamento de neurologistas e a partir dos três meses de idade vem sendo tratado pelo método evolutivo Bobath. Um Terapeuta ocupacional e uma fonaudióloga fazem parte da equipe médica. A despeito do tratamento que recebe, TH apresenta problemas: não fala, não senta sozinho, a cabeça, apesar de cair para trás, apresenta elevação voluntária até a linha mediana, acompanha objetos com os olhos, apresenta retração de ombros, consegue com muita dificuldade elevar as mãos (movimento não voluntário), a sua locomoção é no chão onde rola e se arrasta.

A procura de recursos para proporcionar e facilitar as condições de vida de $\mathrm{TH}$, de forma que ele fosse capaz de trabalhar e de desenvolver suas aptidões, e a procura de tratamentos alternativos que acelerassem suas aquisições motoras, levaram os pais de $\mathrm{TH}$ a entrarem em contato no Canadá com Hugh Macmiliam Reabilitation Center, onde conseguiram o método BLISS para comunicação através de símbolos.

Em 1993, TH entrou, por sorteio, numa escola pública experimental onde estudou até o final do ensino médio. Na sala de aula, TH é tratado como mais um entre os 25 alunos que compõem a classe, com a diferença de que ele precisa da mediação de outra pessoa para se comunicar - habitualmente sua mãe. A sua fórmula básica de comunicação é sim/ não, representada por um simples gesto com a cabeça para frente ou para os lados. Por essa razão, para se comunicar com TH, é importante fazer perguntas que sugiram as respostas sim ou não.

Para conhecer TH um pouco mais, transcreve-se um episódio sobre ele, narrado pela mãe.

TH freqüentava a sexta série de um colégio de Florianópolis. Tínhamos uma moça que o acompanhava em sala de aula para auxiliá-lo nas tarefas e exercícios. Ela ficava com ele quatro vezes por semana e eи uта vez.

Era meu dia aquele. Líamos um texto e ele começou a dizer que não estava conseguindo ler. Tentei ajustar a distância do texto (nós seguramos o texto para ele), fiz perguntas sobre o tamanho da letra, quem sabe o assunto não estava muito interessante... Não era nada daquilo e ele continuou a reclamar, estendendo sua visão para o resto da sala, primeiro, dizendo que não estava enxergando bem as pessoas e, depois, dizendo que, realmente, não conseguia identificar as cores. Tudo isso descobri, fazendo perguntas para ele. À medida que eu fazia as perguntas e ele errava, a minha preocupação aumentava.

Sai da sala para pensar o que fazer e fui para a entrada do colégio. Que maravilha! O meu marido já estava lá nos esperando! Contei para ele o que estava acontecendo. 
Cadernos de Estudos Lingüísticos 48(2) - Jul./Dez. 2006

Imediatamente, ele começou a procurar o número do telefone do oftalmologista que costuma nos atender.

Nem esperamos terminar a aula e saímos, desesperadamente, para o consultório. No caminho, ele insistia em dizer que não enxergava nada. O olhar nos acompanhava quando "falava" conosco, como sempre fazia.

No consultório, o médico dilatou a pupila de TH, examinou-o e NADA! Não era descolamento de retina e ele estava com os reflexos em dia - estava enxergando, só não se sabia dizer o quanto. Marcamos nova consulta para dali a dois dias.

Voltamos para casa e o TH insistia em dizer que não enxergava nada. Os dias seguintes foram terríveis! Finalmente, chegou o dia da consulta.

- "A visão está ótima. Ele tem um pequeno grau de astigmatismo que nem exige correção”. Este foi o diagnóstico do médico. E, agora? O que fazer? Saímos muito tristes do consultório. Entramos no carro e eu comecei a conversar com TH: - Ficastes triste TH? A resposta foi "sim”. Eu disse:- (estávamos em frente de uma ótica) - Quem sabe eu entro naquela ótica e pego um par de óculos para o TH experimentar. Quem sabe ele está é precisando de óculos?

Então, fui até a ótica, peguei um par de óculos do mostruário, levei até o carro e colocamos nele - tinha etiqueta e tudo! Imediatamente, ele começou a dizer que estava enxergando as core, e que estava lendo (confirmávamos, oferecendo respostas certas e erradas e a "certa" ele escolhia). Continuamos a farsa.

Então, saí do carro para entregar o par de óculos na ótica. Quando voltei, o pai do TH estava do lado de fora, cotovelo apoiado no capô do carro, mãos na cabeça. Aliviado, brincando falou:- "Mulher, vai para casa, põe uma cerveja na geladeira e cancela a consulta de hoje à tarde com o oftalmologista e marca uma com um psicólogo!".

Ligamos para o oftalmologista, contamos a história, pedimos que ele aviasse uma receita de óculos. No outro dia, estávamos na ótica, comprando um par de óculos para o TH. Ele ficou lindo e feliz da vida!

A apresentação do episódio, contado pela mãe de TH pretende evidenciar uma das capacidades intelectuais que compõem o pensamento, isto é, a capacidade de raciocínio de TH. Pois, ele apresenta anomalias severas na produção da fala, nunca articulou palavras, e, mesmo assim, comunica-se através de uma linguagem gestual binária de sim e não. Como salientaram Johnson-Laird e Byrne (1990), o raciocínio dedutivo é necessário para que possamos formular planos; avaliar ações alternativas; determinar as consequiências de suposições e hipóteses; interpretar e formular instruções, regras e princípios gerais; realizar argumentações e negociações; pesar evidências e avaliar dados; decidir entre teorias rivais e solucionar problemas.

Assim, uma parte importante do raciocínio para tomar decisões consiste em determinar a probabilidade de certos resultados e avaliar as alternativas relativas entre si. Esta é uma das questões que voltará a ser abordada mais adiante, no experimento 3, no teste de raciocínio - tarefa de seleção de Wason. 
MACEDO - Habilidades cognitivas de um adolescente...

\section{METODOLOGIA}

\subsection{Sujeitos}

São sujeitos desta pesquisa: TH, um adolescente de 15 anos e seis meses, anártrico e portador de tetraplesia e um grupo controle formado por 15 sujeitos falantes, sendo 10 do sexo feminino e 5 do sexo masculino, com idade cronológica média de 14 anos e oito meses. O sujeito mais jovem desta turma tinha 13 anos e 4 meses e o sujeito mais velho tinha 16 anos e 3 meses com um desvio padrão de 0,707 . Para o cálculo das datas foi considerado o último mês de entrevistas - dezembro de 2000 . TH e todos os sujeitos do grupo controle freqüentavam a sétima série de uma escola pública de Florianópolis.

\subsection{Procedimentos}

Em todos os testes experimentais, os sujeitos foram informados de que as suas respostas seriam registradas em uma ficha. Os testes foram feitos em sessões individuais tanto com TH quanto com os sujeitos do grupo controle.

Para se saber a resposta de TH, foi criado o seguinte código: quando TH olhasse firmemente para o pesquisador, no momento em que o pesquisador apontasse para um dos itens - significaria que aquele item era a escolha de TH.

\subsection{Testes}

Nesta pesquisa, todos os testes (teste de inteligência geral - matriz de Raven (1938); categorização - teste de emparelhamento espontâneo de imagens; teste de raciocínio - tarefa de seleção de Wason (1966); memória de curto prazo - tarefa de digit probe-span; teoria da mente - tarefa de falsa crença de primeira ordem, tarefa de falsa crença de segunda ordem e tarefa de falso passo social; e o teste de cognição visual de Palmer (1977), apresentado na forma de uma tarefa part-probe) foram selecionados com o objetivo de colocar em evidência os processos do pensamento utilizado por TH em situações que implicariam raciocínio, atribuição de crença e de inferências, categorização e memória imediata. Fez parte, também, destes experimentos a anamnese.

\subsubsection{Anamnese}

A anamnese se constitui de questões sobre o histórico das condições pré e perinatais de $\mathrm{TH}$, ou seja, as principais etapas do seu desenvolvimento motor, doenças ou internações significativas, aspectos do seu comportamento social bem como aspectos do seu desenvolvimento intelectual. 


\section{DESING}

Este artigo é apresentado da seguinte forma: cada um dos seis experimentos desenvolve o referencial teórico; o experimento; e os resultados. E, no final da apresentação de todos os seis experimentos é exibida a discussão geral.

O objetivo geral destes seis experimentos é o de investigar e o de caracterizar os processos cognitivos de $\mathrm{TH}$, enfatizando, especialmente, o modo como ele representa um material gráfico, como agrupa coisas e eventos em categorias, como realiza um raciocínio dedutivo e/ou indutivo, como faz inferência sobre os estados mentais de outras pessoas, como mantém informações recebidas alguns segundos antes.

A principal hipótese a ser testada neste estudo é a de que o sujeito TH tem um desempenho cognitivo normal; a hipótese alternativa que ele apresentaria deficiências cognitivas nos domínios investigados. Com esse objetivo, a performance de TH será comparada tanto com o escore médio quanto com o escore inferior observado no grupo de sujeitos controles, ou seja, 15 sujeitos controles que freqüentavam a sétima série do ensino fundamental de um colégio experimental de Florianópolis.

O primeiro experimento, denominado de "teste de inteligência geral - matriz de Raven", trata da avaliação da inteligência analítica a partir de material gráfico não verbal. Este teste foi aplicado com o objetivo de comparar os escores de TH com os escores do grupo controle.

$\mathrm{O}$ segundo experimento, denominado de teste de "categorização taxinômica $\mathrm{x}$ funcional", trata de um importante aspecto do comportamento humano, ou melhor, da capacidade de agrupar objetos e acontecimentos em classes ou categorias, de modo que todos os membros de uma classe possam ser tratados, em certos aspectos, como equivalentes. Este teste foi aplicado com o objetivo de não só observar se TH apresentava a capacidade de agrupar coisas e acontecimentos em categorias, mas também de comparar o perfil de suas respostas com o perfil das respostas do grupo controle.

O terceiro experimento, o teste de raciocínio, baseado na tarefa de seleção de Wason (1966), trata de situações que requerem inferências que tenham como base o raciocínio hipotético-dedutivo. Este teste foi apresentado a TH com o objetivo de observar não só se ele sabia apontar, através do olhar, se uma dada proposição era verdadeira ou falsa e apontar aqueles cartões que eram necessários para verificar o que foi dito, mas também observar se TH fazia uso de regras.

O quarto experimento, denominado de teste "teoria da mente: atribuição de crenças e de inferências", trata da habilidade de fazer inferência sobre os estados mentais de outras pessoas. Este teste foi apresentado a TH com o objetivo de observar se ele tinha a habilidade para inferir que outras pessoas podiam ter crenças diferentes das suas (tarefa de falsa crença de primeira ordem), se ele tinha também a habilidade para compreender o que alguém pensava sobre o que outra pessoa pensava (tarefa de falsa crença de segunda ordem), e se ele reconhecia que alguém cometia um lapso ou falso passo social (tarefa de faux pas).

O quinto experimento, denominado de teste de "memória de curto prazo: tarefa de digit probe-span", trata sobre a memória de curto prazo, ou mecanismos cognitivos que nos permitem guardar com eficácia um número limitado de informações por um breve período de tempo (SMITH, E.E., \& GEVA, A., 2000). Este teste foi feito com o objetivo 
MACEDO - Habilidades cognitivas de um adolescente...

de observar se TH mantinha informações verbais recebidas alguns segundos antes da mesma forma que o grupo controle.

O sexto experimento, denominado de "teste de Palmer - tarefa part-probe", trata da cognição visual. O objetivo de apresentar este teste a TH era o de verificar se ele desenvolveu a capacidade de análise visual não-lingüística.

Desta forma, nos cinco primeiros experimentos, o desempenho do sujeito TH é comparado ao desempenho do grupo controle. O teste de Palmer foi realizado, somente, com TH, porque no final do mês de dezembro, época em que foi aplicado o teste de Palmer, os sujeitos controles já se encontravam em férias escolares o que impossibilitou o contato do pesquisador com os sujeitos.

\subsection{Teste de Inteligência Geral - Matriz de Raven (1938)}

A avaliação da inteligência tem a sua história ligada a necessidades sociais de desenvolvimento do comportamento humano. Basicamente, a função das avaliações psicológicas é conhecer as diferenças entre indivíduos.

Ao contrário de vários outros testes que visam medir a "inteligência geral", os testes ditos perceptivos - entre os mais conhecidos estão o Test de Cattell (IPAT) e as Matrizes de Raven - não implicam manipulação de material concreto nem interpretação de imagens (representação de objetos ou de cenas). Neste tipo de teste, o recurso de utilizar figuras geométricas visava responder à objeção (vinda, principalmente, de antropólogos) e segundo a qual os mesmos objetos podiam ter diversas significações em diferentes culturas. Levando em consideração essa perspectiva, as matrizes de Raven são consideradas como sendo um teste de raciocínio analítico sobre um material visual constituído por formas geométricas.

As matrizes de Raven existem sob três formas que variam segundo o grau de dificuldade. Citam-se por ordem decrescente de dificuldade, "Matriz Progressiva Colorida - CPM ou PM47-", "Matrizes Progressivas Padrão - SPM ou PM38" -, e "Matrizes Progressivas Avançadas - APM-".

Os itens compreendem disposições em linhas e em colunas de $n$ elementos dos quais um é uma lacuna sempre situada embaixo e à direita. A tarefa do sujeito é a de escolher entre um conjunto de $n$ figuras aquela que é adequada para preencher o vazio. Os itens mais fáceis exigem somente uma discriminação relativamente simples, enquanto que os mais difíceis exigem capacidades de raciocínio abstrato no que diz respeito ao material visual. Trata-se de um teste cujas instruções verbais dadas oralmente são simples e cuja transmissão pode, em função dos sujeitos examinados, ser feita sem limite de tempo.

$\mathrm{Na}$ verdade, os testes de inteligência devem ser, preferencialmente, considerados como uma medida de adaptação sócio-cultural, inclusive escolar, do indivíduo examinado. Com efeito, apesar do fato de que testes tais como as Matrizes Progressivas sejam consideradas como "culture-fair", isto é, como um reflexo fiel das faculdades de raciocínio analítico, estudos mostram uma correlação relativamente alta entre o grau de escolarização e os escores da Matriz Progressiva de Raven (CECI \& WILLIAMS, 1997; KOLINSKY, 1996; 1999; SCHMIDT, 1967; VERHAEGHE, 1999).

Neste trabalho, utiliza-se o teste da Matriz de Raven (1938) com o objetivo de comparar os escores de TH com os escores do grupo controle. 


\subsubsection{Experimento 1: Teste de Inteligência Geral - Matriz de Raven (1938)}

O teste de Inteligência Geral - Matriz de Raven - foi apresentado, a cada sujeito, com o objetivo de comparar os escores de $\mathrm{TH}$ com os escores do grupo controle.

O teste foi apresentado da seguinte maneira: sessenta itens gráficos foram apresentados pelo pesquisador aos sujeitos, sendo que os primeiros 24 itens ofereciam seis (6) respostas para serem escolhidas e os 36 itens seguintes ofereciam oito (8) respostas para serem escolhidas. O teste apresentava, a cada 12 questões, um grau crescente de dificuldade e complexidade. Nota-se que, em razão de TH não conseguir manusear material, o pesquisador mostrou não somente a ele cada item, mas também aos outros sujeitos. Neste teste não foi observado o tempo de reação de nenhum sujeito em razão de que TH apresentava dificuldades para fixar os itens para depois analisá-los.

Houve uma fase de treino em que as respostas eram aprovadas ou corrigidas verbalmente. Somente, após a compreensão da tarefa que se passou para os testes.

$\mathrm{Na}$ análise dos resultados foram observados os resultado bruto e o percentual de respostas corretas.

\subsubsection{Resultados do experimento 1}

Os resultados deste teste, apresentados no gráfico 1 (em vermelho: a média de respostas certas de TH; em azul: as médias de cada um dos 15 controles), demonstram que enquanto TH acerta 16 questões, ou seja, 26,67\% das questões, a média de acerto do grupo controle é de 33,73 questões, ou seja, $56,22 \%$ de acerto (desvio padrão: 15,22). O mínimo de respostas corretas observada no grupo controle foi de $38,33 \%$, o desempenho de $\mathrm{TH}$ pode ser considerado inferior e anormal frente ao grupo controle. $\mathrm{O}$ teste não-paramétrico de $\mathrm{c}^{2}$, comparado ao número de sucessos e fracassos para TH e (na média) no grupo controle, confirma essa que $\mathrm{TH}$ alcançou um escore significativamente mais baixo do que aquele do grupo controle $\left(\mathrm{c}^{2}(1)=9.9, \underline{\mathrm{p}}<.005\right)$.

Gráfico 1: Teste de Inteligência Geral - Matriz de Raven 1938.

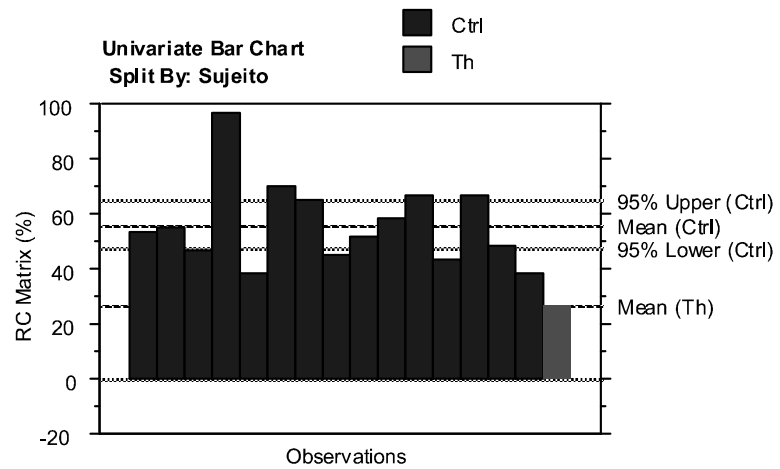


MACEDO - Habilidades cognitivas de um adolescente...

Como o teste apresenta, a cada 12 questões, um grau crescente de dificuldade e complexidade, observou-se, nas respostas de $\mathrm{TH}$, que nos primeiros 12 itens ele acertou 8 questões, nos 12 itens seguintes acertou 3, nos 12 itens subseqüentes 2 , nos 12 itens imediatos 1 e nos últimos 12 ítens 2 . Os resultados indicam que TH se saiu bem, somente, nos 12 primeiros itens, ou seja, os mais fáceis e mais simples. Já, o grupo controle, nos primeiros 12 itens teve a média de 9,86, o mínimo de 8 e o máximo de 12 acertos, nos 12 itens seguintes teve a média de 8,33, o mínimo de 6 e o máximo de 12 acertos, nos 12 itens subseqüentes teve a média de 6,13, o mínimo de 2 e o máximo de 11 acertos, nos 12 itens imediatos teve a média de 6,46, o mínimo de 1 e o máximo de 11 acertos e nos últimos 12 itens teve uma média de 2,93, o mínimo de zero e o máximo de 12 acertos. Deste modo, o desempenho médio do grupo controle apresenta o mesmo perfil de TH.

Portanto, os resultados indicam que TH apresenta problemas ou de raciocínio analítico, ou de percepção ou de cognição visual.

\subsection{Categorização Taxonômica $x$ Funcional - Teste de Emparelhamento Espontâneo de Imagens}

O comportamento humano é dominado pelo uso de linguagem, ou seja, o uso de símbolos para representar idéias, eventos, objetos, ações, sentimentos, relações e todos os outros aspectos da experiência. Graças à concordância sobre aquilo a que cada símbolo se refere e sobre a maneira como os símbolos podem ser combinados em sequiências, os indivíduos estão aptos a comunicar-se entre si.

Um importante aspecto do comportamento humano é a capacidade de agrupar coisas e acontecimentos em classes ou categorias, de modo que todos os membros de uma classe possam ser tratados, em certos aspectos, como equivalentes. Como por exemplo, os sólidos formam uma categoria distinta de substâncias da dos líquidos e gases, e o conhecimento de que determinada substância é um sólido, habilita-nos a inferir algumas de suas propriedades. O processo de categorização é importante porque ao reduzir o número de diferentes tipos de objetos e eventos com que se lida no dia-a-dia, simplifica um mundo complexo. A categorização, o estabelecimento de semelhanças, é o inverso da discriminação, o estabelecimento de diferenças entre coisas e eventos. $\mathrm{O}$ uso da linguagem implica que a categorização e a discriminação devem ser possíveis, quando estão envolvidas as representações verbais de coisas e eventos reais; e a memória semântica deve conter informações suficientes para permitir que esses processos ocorram.

Teóricos do desenvolvimento têm sugerido que crianças são sensíveis às propriedades funcionais das palavras desde os primeiros anos de vida (MANDLER, 1994). Estudos indicam que o pensamento funcional tem um papel importante no desenvolvimento da linguagem. Moss et al. (1977) encontraram, em adultos, um efeito maior de priming semântico para palavras relacionadas com propriedades funcionais do que para palavras que têm outras propriedades semânticas. Estes achados sustentam a visão de que a informação funcional, talvez, mais do que a informação categorial seja central para o significado das palavras e que esta informação é, automaticamente, processada (MOSS et al., 1977). 
Cadernos de Estudos Lingüísticos 48(2) - Jul./Dez. 2006

Nelson (1986) sugere que as relações taxionômicas desenvolvem-se a partir das experiências cotidianas representadas em forma de scripts ou de esquema funcional. E, ainda, segundo ele, até dez anos de idade as crianças preferem relações temáticas a relações taxonômicas.

Pesquisas sobre representação categorial têm sido feitas com o objetivo de compreender o desenvolvimento de conceitos científicos em crianças. Por conceito científico, Vygotsky (1962) diz ser o desenvolvimento de um sistema "hierárquico de interrelações" que forma a base de "consciência refletiva".

Uma das conclusões vindas dos trabalhos de Vygotsty é que a representação taxonômica não emerge em crianças antes dos oito ou nove anos de idade. Com bases teóricas diferentes, Piaget (INHELDER \& PIAGET, 1964) conclui que crianças, com menos de 10 ou 11 anos de idade, são incapazes de formar representações taxionômicas superiores. Nelson (1977; 1982) propõe que crianças representam informações e eventos, em geral, baseadas em scripts que mantêm uma relação espacial e temporal entre os objetos. Por exemplo, cabeça e chapéu podem ser relacionados como um script porque os objetos, funcionalmente, se relacionam no mundo real. A partir desta base de conhecimento, Houdé (1989) relacionou estes resultados à performance na tarefa de classe de inclusão de Piaget, argüindo que crianças antes dos dez anos de idade tendem a solucionar problemas, usando esquemas funcionais ao invés de relações lógicas. Segundo Petrey (1977), nas tarefas de associação, as crianças mais jovens estão mais propensas a escolher nomes que estão relacionados à função da palavra alvo do que nomes que são relacionados a categorias co-ordenadas da palavra alvo. De forma similar, usando "cued recall", Blewitt e Toppino (1991) encontraram nas respostas dos testes que as crianças são melhores em associar pares de palavras relacionadas com o pensamento funcional (cadeira-sala, avião-céu), do que com pares de palavras que sugeriam a mesma categoria (cadeira-cama, avião-trem).

Morais e Kolinsky (1999) confirmaram a inclinação demonstrada por Luria (1976) de que sujeitos iletrados e ex-iletrados emparelham itens mais sobre bases de relações funcionais do que taxonômicas. No entanto, Morais e Kolinsky (1999) encontraram não somente nas tarefas de emparelhamento, mas também na tarefa de fluência verbal, que crianças pré-escolares e indivíduos iletrados possuem uma memória semântica organizada de maneira taxonômica e hierárquica, o que não exclui que iletrados apresentem, também, uma organização esquemática e funcional. Conseqüentemente, algumas relações semânticas predominam sobre outras (ROSS \& MURPHY, 1999; VALLÉE-TOURANGEAU, ANTHONY \& AUSTIN, 1998).

Outros pesquisadores têm argumentado que estruturas taxonômicas não são evidentes em crianças de sete ou oito anos de idade (GELMAN \& O'REILLY, 1988). Além do mais, Markman e Callanan (1984) pontuam que embora as crianças pequenas façam uso de termos superordinado como animais ou brinquedos, não significa que elas tenham a compreensão das relações transitivas assimétricas que definem a taxionomia, ou seja, as crianças podem usar o termo animal para significar cachorro, sem compreender que todos os cachorros são animais e que nem todos animais são cachorro. Finalmente, os trabalhos de Gelman e O'Reilly (1988) confirmam os estudos acima, mostrando as dificuldades de se formar relações superordinada em crianças de cinco e oito anos de idade. 
MACEDO - Habilidades cognitivas de um adolescente...

Este estudo pretende observar como TH categoriza, utilizando o método de tríade. Ou seja: é apresentada a TH e aos sujeitos controles uma palavra alvo que deverá relacionarse com uma segunda palavra, funcional ou taxonômica, à escolha dos sujeitos.

\subsubsection{Experimento 2: Categorização taxinômica $x$ funcional - Teste de Emparelhamento Espontâneo de Imagens}

O experimento foi composto por vinte itens alvo, formando um total de sessenta imagens, já que cada item alvo era apresentado com mais dois itens, um que mantinha uma relação funcional e outro que mantinha uma relação taxonômica com o alvo. As imagens deste material fazem parte do conjunto de Snodgrass e Vanderwart (1980), e o teste foi feito por Morais, Kolinsky e Scliar-Cabral no quadro da pesquisa da tese de Rosemeire Monteiro, doutoranda da UFSC.

Para a apresentação deste teste foram utilizados cartões brancos com imagens, em preto e branco, de animais, objetos, comidas e partes do corpo, todos familiares aos sujeitos. A figura 1 exemplifica a tarefa de emparelhamento de imagens. Na tarefa perguntava-se aos sujeitos, por exemplo, pão combina mais com boca (resposta funcional-associativa) ou com bolo (resposta taxonômica)?

Figura 1: tarefa de emparelhamento de imagens.
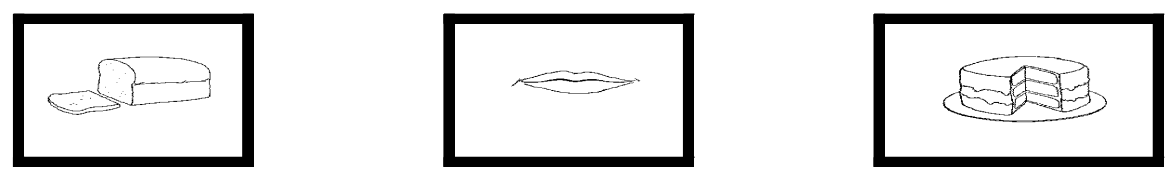

Aos sujeitos as respostas foram apresentadas em cartões de $10 \mathrm{~cm}$ de altura por 10 $\mathrm{cm}$ de largura, dispostos lado a lado, com distâncias de $50 \mathrm{~cm}$, principalmente, para forçar que TH olhasse para direita, centro e esquerda, - o olhar firme de TH para um dado cartão significava - resposta correta.

Em cada ensaio, o experimentador colocava, primeiro, uma imagem (1) na frente do sujeito - item alvo, depois duas outras imagens, uma à esquerda (2), outra à direita (3), e o sujeito devia escolher entre (2) e (3) a que melhor emparelhava com (1).

Houve uma fase de treino em que as respostas eram aprovadas ou corrigidas verbalmente. Somente, após a compreensão da tarefa que se passou para os testes.

\subsubsection{Resultados do experimento 2}

Os resultados deste teste demonstraram, nos sujeitos controles, uma escolha mais frequiente para respostas relacionadas com propriedades funcionais $(62.33 \%$ das respostas, na média, um desvio padrão de 23,$82 ; \max =100 \% \min =20 \%$ ) do que com propriedades taxionômicas $(37.67 \%$ das respostas, na média, com um desvio padrão de 23,82; max = $80 \% \min =0)$. 
Cadernos de Estudos Lingüísticos 48(2) - Jul./Dez. 2006

Quanto à TH, observa-se nos resultados dos testes que ele, também, realizou uma escolha mais freqüente para respostas relacionadas com propriedades funcionais $(70 \%$ das respostas) do que taxonômicas (30\% das respostas). Portanto, como os sujeitos controles, tende a utilizar mais esquemas funcionais - relação dos objetos no mundo real - ao invés de relações lógicas para solucionar seus problemas. A diferença entre TH et os sujeitos controles não é significativa $\left(c^{2}<1\right)$. Portanto, os resultados sugerem que TH se encontra dentro da normalidade frente ao grupo controle.

\subsection{Raciocínio: Tarefa de seleção de Wason - (1966)}

O raciocínio lógico é uma das capacidades intelectuais importantes que compõe o pensamento (JOHNSON-LAIRD \& BYRNE, 1990).

Em sua forma original, a tarefa de seleção, proposta por Wason (1966), em sua forma original, propõe mostrar aos sujeitos quatro cartas com uma letra numa face e um número na outra face. Por exemplo, os sujeitos vêem as 4 cartas "E" "K" "2" "5". Informa-se aos sujeitos que cada uma destas cartas tem uma letra em um lado e um número do outro lado, e a tarefa dos sujeitos é nomear as cartas que precisam ser viradas para que se possa testar a seguinte regra: "se existe uma vogal em um lado da carta, então existe um número par do outro lado da carta". No formalismo lógico, essa regra da tarefa de seleção poderia ser expressa pela forma condicional [Se P, então Q], onde [P] representa a proposição "se existe uma vogal em um lado da carta" e [Q] representa a proposição "existe um número par do outro lado". Os sujeitos recebem a instrução de virar apenas aquelas cartas necessárias. A resposta correta é virar apenas duas cartas. De fato, a única maneira de verificar a regra e tentar falsificá-la, ou seja, virar a carta, apresentando, o [P] (no exemplo, a carta que tem o E) para verificar se existe um [não-Q] (um número impar) do outro lado e de virar [não-Q] (no exemplo, a carta que tem o 5) para verificar se existe um [P] (uma vogal) do outro lado.

A partir das pesquisas, nota-se que um número reduzido de sujeitos fazem as escolhas correta. Na pesquisa de Johnson-Laird e Wason (1970), apenas cinco sujeitos de um total de 128 escolheram apenas as cartas [P] e [não-Q]. A maioria dos sujeitos escolheu ou as cartas [P] e [Q] (59 de 128); ou apenas a carta [P] (42 de 128).

Muitas tentativas foram realizadas para tentar explicar o comportamento demonstrado nesta tarefa (COSMIDES, 1989; EVANS, 1989; MARGOLIS, 1987). Inicialmente, pensavase que o comportamento dos sujeitos era o resultado de uma tentativa de verificar a regra ao invés de falsificá-la, ou seja, os sujeitos viram a carta [P] (apresentando a vogal) para ver se existe um [Q] (um número par) do outro lado e a carta [Q] (apresentando um numero par) para ver se existe um [P] (uma vogal) do outro lado (Wason \& Johnson-Laird, 1972). Segundo Evans, 1989, a resposta [P - Q] é conhecida como matching biais. A escolha da carta [Q] não é uma escolha adequada porque, quando o [Q] é verdadeiro e a regra se [P] então [Q] é verdadeira, o [P] pode ser ou verdadeiro ou: não importa o que tiver do outro lado da carta, a regra será verdadeira falso (EVANS, 1989). Assim, parece não ser interessante virar esta carta. Muitos sujeitos que viram a carta [Q] podem estar fazendo uma inferência errada da afirmação do conseqüente; eles assumem que a regra se [P] então 
MACEDO - Habilidades cognitivas de um adolescente...

$[\mathrm{Q}]$ é verdadeira, ele sabem que [Q] é verdadeiro e assim eles concluem que [P] deve estar do outro lado da carta. Desta forma, se [não - P] está do outro lado, eles concluem que a regra não é verdadeira.

Por outro lado, a escolha da carta [P] e da carta [não-Q] é correta, pois, realizam-se inferências logicamente válidas que podem tornar falsa a regra. Quando o $[\mathrm{P}]$ é verdadeiro e a carta é virada, então o que é encontrado do outro lado indica se a regra é verdadeira ou falsa. Se [Q] estiver do outro lado, então a regra é verdadeira, e se é o [não-Q], então a regra é falsa. De maneira semelhante, se a carta virada é uma [não-Q] então se aparecer do outro lado da carta um [P], a regra é falsa.

Mas uma das descobertas que também surgiu com a tarefa do Wason é de que o desempenho dos sujeitos é bem melhor se a tarefa for apresentada com materiais concreto, temáticos ou realistas. Assim, os efeitos de materiais concretos sobre a tarefa de seleção de Wason levaram alguns pesquisadores a concluírem que as pessoas utilizam regras específicas a um domínio ao invés de regras gerais, independentes de domínio (HOLT, RINEHART \& WINSTON, 1996 - Trad. por Sternberg, 2000).

A tarefa de seleção foi apresentada a TH com o objetivo de observar se ele sabe identificar se uma dada proposição é verdadeira ou falsa e apontar, através do olhar, aqueles cartões que são necessários para verificar o que foi dito. Para a apresentação deste teste, ao invés de servir-se de números e vogais, como na tarefa original proposta por Wason (1966), foram utilizados cartões com imagens familiares aos sujeitos. Esse teste foi adaptado por Elias J. Mengarda para examinar sujeitos brasileiros no seu trabalho "Efeitos da escolarização e do letramento no desenvolvimento da capacidade de resolução de problemas baseados em correspondências".

\subsubsection{Experimento 3: Teste de Raciocínio - tarefa de seleção de Wason - (1966)}

O experimento foi composto por cinco sub-tarefas, e para cada uma havia duas questões. Foram utilizados cartões com imagens familiares aos sujeitos, ou seja, jogadores de futebol com suas respectivas camisas do time; jogador de tênis e de basquete com um dos respectivos equipamentos necessários para cada tipo de jogo - raquete e bola; meios de transportes marítimo e ferroviário com suas respectivas vias; políticos nacionais e estaduais com suas respectivas bandeiras. Em cada cartão havia uma imagem de um lado e outra diferente, no outro lado. Aos sujeitos é mostrado um conjunto de quatro cartões. Em cada cartão tem uma foto num lado e outra, diferente, no outro lado do cartão. O comando para orientar a aplicação da tarefa foi o seguinte: "Veja este conjunto de 4 cartões, por exemplo. Num lado você vê o Romário e no outro lado você vê a camisa do flamengo. Nesse outro cartão temos a foto do Marcelinho Carioca e no outro lado a camisa do Corinthias". Exemplifica-se, utilizando um conjunto de cartas numeradas seguindo a ordem da esquerda para a direita (com o lado visível em negrito e o lado virado para baixo entre parênteses. 1a carta: Romário/(camisa do Flamengo) - 2a carta: camisa do Corinthias/ (Romário) - 3a carta: camisa do Flamengo/(Marcelinho Carioca) - 4a carta: Marcelinho Carioca/(camisa do Corinthias). 
Cadernos de Estudos Lingüísticos 48(2) - Jul./Dez. 2006

A questão em relação a este conjunto de cartões é a seguinte: "Se há o Romário em um lado do cartão, então há a camisa do Flamengo no outro lado do cartão". O sujeito deve dizer se esta proposição é verdadeira ou falsa e para isto os sujeitos controles devem dizer aqueles cartões que são necessários para verificar o que foi dito. Já, TH deve apontar com o olhar fixo para demonstrar o mesmo. Os sujeitos recebem a instrução de virar apenas aquelas cartões necessários. A resposta correta é virar apenas dois cartões: $P$ ( Romário) e [não-Q] (camisa do Corinthias).

Aos sujeitos a tarefa foi apresentada em cartões com imagens coloridas, $10 \mathrm{~cm}$ de largura por $10 \mathrm{~cm}$ de altura, dispostos lado a lado, com distâncias de $50 \mathrm{~cm}$, principalmente, para forçar que TH olhasse para direita, centro e esquerda, o olhar firme de TH para um dado cartão significava a resposta que ele havia escolhido.

Houve uma fase de treino onde as respostas eram aprovadas ou corrigidas verbalmente. Somente, após a compreensão da tarefa que se passou para os testes.

\subsubsection{Resultados do experimento 3}

O número médio de cada um dos vários tipos de respostas observadas está apresentado na tabela abaixo, junto com o desvio padrão, máximo e mínimo para os sujeitos controles. Na tabela 1, nota-se que TH não é diferente do grupo controle, pois apresenta $30 \%$ de respostas certas vs. $16 \%$ para o grupo controle.

Tabela 1: Tarefa de Wason - numero médio, desvio padrão, máximo e mínimo

\begin{tabular}{|c|c|c|c|c|c|c|}
\hline & $\mathrm{P}[\mathrm{N}-\mathrm{Q}]$ & $P-Q$ & $\mathrm{P}[\mathrm{N}-\mathrm{P}]$ & {$[\mathrm{N}-\mathrm{Q}[\mathrm{N}-\mathrm{P}]$} & {$[\mathrm{N}-\mathrm{Q}] \mathrm{Q}$} & {$[\mathrm{N}-\mathrm{P}] \mathrm{Q}$} \\
\hline Média - Controles & 1,6 & 2,67 & 4,27 & 0,93 & 0,53 & 0,07 \\
\hline Desvio Padrão & 1,8822479 & 1,99 & 2,34 & 1,98 & 0,83 & 0,26 \\
\hline Mínimo & 0 & 1 & 0 & 0 & 0 & 0 \\
\hline Máximo & 6 & 8 & 8 & 7 & 2 & 1 \\
\hline $\mathrm{TH}$ & 3 & 1 & 6 & 0 & 0 & 0 \\
\hline
\end{tabular}

Em ambos, TH e grupo controle, a resposta mais freqüente foi P [N-P]. Supõe-se que essa resposta foi a mais escolhida porque a escolha $[\mathrm{P}]$ ficou entendida para os sujeitos que o primeiro cartão mencionada serviria de pista e, então, deveria ser o primeiro cartão a ser apontada. A resposta [N-P] foi uma escolha surpreendente, pois esse cartão não foi mencionado na questão.

Para tentar esclarecer utiliza-se o mesmo exemplo já mencionado, ou seja, um conjunto de cartões numerados, seguindo a ordem da esquerda para a direita (com o lado visível em 
MACEDO - Habilidades cognitivas de um adolescente...

negrito e o lado virado para baixo entre parênteses: 1a carta: Romário/(camisa do Flamengo)

- 2a carta: camisa do Corinthias/(Romário) - 3a carta: camisa do Flamengo/(Marcelinho Carioca) - 4a carta: Marcelinho Carioca/(camisa do Corinthias).

A questão foi: "Se há o Romário em um lado do cartão, então há a camisa do Flamengo no outro lado do cartão".

Supõe-se que os passos dos sujeitos que fizeram a escolha P[N-P] foram os seguintes: primeiro passo: apontar a 1a carta: Romário (carta mencionada/pista indireta); segundo passo: eliminar a 3a carta: camisa do Flamengo (carta mencionada para ser encontrada no outro lado da carta, portanto, carta eliminada) ; terceiro passo: escolher entre a carta 2: camisa do Corinthias e a carta 4: Marcelinho Carioca. Supõe-se que o sujeito escolhe a carta 4: Marcelinho Carioca porque, a partir do comando da tarefa, o sujeito tem conhecimento que não poderia ter duas camisas de time no mesmo cartão (lado visível camisa do Corinthias e lado virado - camisa do Flamengo).

\subsection{Teoria da Mente: Atribuição de crenças e de inferências}

Normalmente, as pessoas usam pistas (expressão facial, tom de voz...) para prever o comportamento de outras pessoas. Esta habilidade de fazer inferência sobre os estados mentais de outros é chamado de teoria da mente (PREMACK \& WOODRUFF, 1978; WELLMAN,1990).

A estrutura do mecanismo da teoria da mente pode ser explicada, examinando-se o que acontece quando existe um rompimento em algum estágio particular de desenvolvimento. A teoria da mente se manifesta em atenção conjunta e em indicação proto-declarativa (BARON-COHEN, 1989a , 1995) em crianças por volta dos 18 meses de idade. Por atenção conjunta, entende-se que a criança é capaz de saber não somente o que outra pessoa está olhando, mas também que ela poderia estar olhando para o mesmo objeto. Ou seja, antes dos 18 meses de idade, a criança é capaz de compreender o fato de que "mamãe vê o brinquedo", mas por volta dos 18 meses, a criança começa a entender "mamãe vê o brinquedo que eu vejo". Na indicação proto-declarativa, a criança usa apontar para chamar a atenção do adulto para o objeto que ela quer que o adulto olhe. O estágio seguinte, no desenvolvimento da teoria da mente, é o jogo do faz de conta no qual a criança é capaz de separar o que é simulação do que é realidade (GOPNIK \& ASTINGTON, 1988; WIMMER \& PERNER, 1983). Entre os 18 e 24 meses de idade, a criança começa a compreender os estados mentais de fingir (LESLIE, 1987). Também, por volta dos 2 anos de idade, a criança parece ter a compreensão dos estados mentais do desejo, por exemplo, ela começa a compreender que "João quer hambúrguer" (WELLMAN \& WOOLLEY, 1990).

Entre os 3 e 4 anos de idade, a criança desenvolve a habilidade de compreender "falsa crença" (GOPNIK \& ASLINGTON, 1988; JOHNSON \& WELLMAN, 1980; WELLMAN, 1990; WIMMER \& PERNER, 1983; STONE, BARON-COHEN E KNIGHT, 1998). Antes desta idade, a criança não compreende que outras pessoas podem ter crenças, opiniões, convicções que diferem de sua crença. Assim, estas crianças assumem que outras pessoas conhecem as mesmas coisas que elas conhecem. 
Entre 4 e 5 anos de idade, as crianças podem aceitar que João tenha uma falsa crença, mas não compreendem a atitude de João em relação a sua atitude (PERNER \& HOWES, 1992). Aquilo que se pensa que o outro pensa (do ponto de vista do outro) constitui uma metarepresentação ou atribuição de uma segunda ordem, uma vez que no primeiro nível (aquilo que o outro pensa) diz respeito, ainda, ao ponto de vista do sujeito. Na escola, observa-se ainda, durante algum tempo, esta tendência para identificar a sua própria interpretação com aquela do autor do texto. Beal (1990) leu para crianças estórias que tinham uma referência implícita e as crianças deveriam indicar se a estória dizia, realmente, que "as ondas tinham destruído o castelo". Somente as crianças com idade entre 8 e 9 anos de idade foram capazes de distinguir entre "dizer" e "querer dizer", entre o que o texto diz e aquilo que elas mesmas tinham inferido do texto.

Entre os 6 e 7 anos de idade, as crianças começam a compreender que outras pessoas podem também representar estados mentais. Nesta fase, a criança começa a ser capaz de compreender falsas crenças de segunda ordem, "crença sobre a crença" (PERNER \& WIMMER, 1985 E STONE, BARON-COHEN E KNIGHT, 1998). Uma tarefa típica de falsa crença de segunda ordem pode ser exemplificada pelo seguinte contexto: um homem e uma mulher estão na sala. $\mathrm{O}$ homem coloca um objeto em algum lugar. A mulher sai da sala. O homem esconde aquele objeto em um outro lugar. Sem o conhecimento dele, a mulher está espiando pela fechadura e o vê escondendo o objeto em outro lugar. Ao sujeito é perguntado: "Quando a mulher voltar, onde o homem crê que a mulher vai pensar que está o objeto?”.

Para resolver este problema, a criança precisa ser capaz de representar não só o estado de crença do homem e da mulher sobre o lugar do objeto, mas também a crença errada do homem sobre o estado de crença da mulher.

Mais tarde, entre os 9 e 11 anos de idade, as crianças desenvolvem a habilidade de compreender e reconhecer um "faux pas" - ou lapso social (STONE, BARON-COHEN E KNIGHT , 1998). Um “faux pas” ocorre quando alguém, por não saber ou não perceber, diz alguma coisa que não deveria ter dito. Por exemplo, Jane comprou de presente de casamento para a amiga Ana uma vaso de cristal. Depois de um ano da data do casamento, Jane foi visitar Ana. Jane derrubou, acidentalmente, o vaso de cristal. O vaso se quebrou. Jane pede desculpas por ter quebrado o vaso. Ana responde, dizendo que, de qualquer forma, nunca gostou do vaso. Para compreender que um "faux pas” ocorreu, alguém tem que representar dois estados mentais. Primeiro, uma pessoa diz o que não deveria dizer e segundo, a pessoa que ouve pode se sentir magoada ou insultada. Assim, existe tanto um componente cognitivo quanto afetivo.

A partir das respostas do teste "faux pas" realizado por Baron-Cohen, O'Ricordan, Stone, Jones e Plaited (1977), descobriu-se que meninas desempenham bem esta tarefa por volta dos 9 anos de idade, já os meninos, por volta dos 11 anos de idade. Meninos e meninas por volta de 7 e 8 anos de idade, embora possam passar no teste de falsa crença de primeira e segunda ordem, não desenvolvem bem a tarefa de "faux pas".

De maneira geral, crianças autistas apresentam graves dificuldades nos testes de teoria da mente (BARON-COHEN, 1995). Segundo Baron-Cohen et al. (1997), a partir dos testes de detenção de faux pas, indivíduos com síndrome de Asperger poderiam passar nas 
MACEDO - Habilidades cognitivas de um adolescente...

tarefas de falsa crença de primeira e segunda ordem, mas seriam prejudicados na tarefa de faux pas. De acordo com Stone, Baron-Cohen, Knight, (1998), a tarefa de faux pas é uma boa medida da teoria de déficits mentais sutis.

O objetivo de aplicar o teste de falsa crença de primeira e segunda ordem em TH foi, no primeiro, observar a sua habilidade para compreender que outras pessoas podem ter crenças diferentes das suas e, no segundo, observar se TH compreende que alguém pensa sobre o que outra pessoa pensa. A tarefa de "faux pas" tem como objetivo verificar se TH distingue quando alguém, por não saber ou não perceber, diz alguma coisa que não deveria ter dito.

Os testes e as histórias apresentados, neste experimento, foram, diretamente, adaptados de Stone, Baron-Cohen \& Knight (1998).

\subsubsection{Experimento 4: Teoria da Mente: Atribuição de Crenças e de Inferências}

Este experimento contém 5 tarefas. Ou seja: uma tarefa de falsa crença de primeira ordem, duas tarefas de falsa crença de segunda ordem e uma tarefa de faux pas. Todas elas são apresentadas, individualmente, a cada sujeito. As tarefas têm uma graduação crescente de complexidade.

A tarefa de falsa crença de primeira ordem é planejada com o objetivo de observar se TH infere que pode haver uma crença que é diferente de sua própria crença; a tarefa de falsa crença de segunda ordem é planejada com o objetivo de observar se TH tem a habilidade de compreender o que uma pessoa pensa sobre aquilo que outra pessoa pensa e, finalmente, a tarefa de "faux pas" é planejada com o objetivo de observar se TH percebe que alguém cometeu um lapso social.

Apresentam-se as questões utilizadas nas tarefas: "Onde o Pedro pensa que está o livro?", apresentada na tarefa de falsa crença de primeira ordem: "Quando Ana voltar, onde Jane pensa que Ana pensa que está o vaso de flores ?", apresentada na tarefa de falsa crença de segunda ordem; e "Alguém disse alguma coisa que não deveria ter dito?", apresentada na tarefa de "faux pas". É, importante mencionar que em uma das tarefas de falsa crença de segunda ordem foi incluída uma questão de inferência não-mental, mas de ordem física "Onde teria farelo de bolacha?".

As duas questões controles, essenciais para a interpretação dos resultados, são as seguintes:

1) Questões que concernem à realidade :’Onde está o livro?", na tarefa de falsa crença de primeira ordem: "Onde está o vaso de flores?", na tarefa de falsa crença de segunda ordem; e "Quem disse alguma coisa que não deveria ter dito?", na tarefa de "faux pás".

2) Questões que concernem à memória: "Onde o Pedro colocou primeiro o livro?", na tarefa de falsa crença de primeira ordem; "Onde estava o vaso de flores no início?", na tarefa de falsa crença de segunda ordem; e "Por que Sara disse que teria uma festa?", na tarefa de faux pas.

Aos sujeitos foram lidas, em voz alta, cinco histórias. Cada história foi apresentada aos sujeitos com uma única leitura. 
Em função da deficiência motora de TH, não foi pedido aos sujeitos controles que justificassem suas respostas nas tarefas. Portanto, são apresentadas questões com respostas de múltipla escolha. Para TH, as respostas foram apresentadas em cartões de $15 \mathrm{~cm}$ de altura por $15 \mathrm{~cm}$ de largura, dispostos lado a lado, com distâncias de $50 \mathrm{~cm}$, para forçar que ele olhasse para direita, centro e esquerda, - o olhar firme de TH para um dado cartão significava - resposta correta.

Houve uma fase de treino em que as respostas eram aprovadas ou corrigidas verbalmente. Somente, após a compreensão da tarefa que se passou para os testes.

\subsubsection{Resultados do experimento 4}

As tarefas de falsa crença de primeira ordem e falsa crença de segunda ordem A e B são desenvolvidas a partir de 3 questões. Uma questão que envolve a crença, uma segunda questão que envolve a realidade e uma última questão que envolve a memória. Em uma das tarefas de falsa crença de segunda ordem foi incluída uma questão de inferência nãomental, mas de ordem física. Nesta questão não foram considerados os erros de "crença" para aqueles sujeitos, que para a mesma história, não fizeram erros nas questões de realidade e/ou memória e/ou inferências físicas.

$\mathrm{Na}$ tarefa de falsa crença de primeira ordem, para a questão de crença tanto $\mathrm{TH}$ quanto todos os 15 sujeitos controles responderam de modo certo. Portanto, TH pode inferir que pode haver uma crença errada que é diferente de sua própria crença,

Nas duas tarefas de falsa crença de segunda ordem, só dois sujeitos do grupo controle apresentaram erro para a questão de crença. Um deles apresentou problemas para as questões controles de memória. Respondeu de forma incorreta.

Quanto a TH, na tarefa de falsa crença de segunda, na primeira questão ele respondeu corretamente, já na segunda questão, ele não só apontou a resposta não esperada "no armário" mas, também, apresentou problemas na questão controle de realidade.

As tarefas de "faux pas" são desenvolvidas a partir de 4 questões. A primeira envolve a existência de um lapso social; a segunda envolve a compreensão do lapso, a terceira necessita da compreensão mental do estado do ouvinte e a quarta envolve a compreensão do estado mental do falante.

$\mathrm{Na}$ tarefa de "faux pas", à questão do reconhecimento da existência de um lapso social "alguém disse alguma coisa que não deveria ter dito?", todos os sujeitos controles deram a resposta esperada. TH respondeu "não sei"1, mas, depois, acertou a questão de compreensão de "faux pas". Nas duas questões seguintes, na compreensão do estado mental do ouvinte e na compreensão do estado mental do falante TH acertou as questões.

Com base nas respostas da tarefa de crença de segunda ordem, onde TH demonstrou ora ter, ora não ter habilidade de compreender o que uma pessoa pensa sobre aquilo que outra pessoa pensa, ficou impossível de decidir se TH apresenta problemas ou não.

Outro ponto que merece consideração neste teste foi o fato de TH, na tarefa de "faux pás”, ter compreendido a história, mas não ter percebido que alguém disse alguma coisa que não deveria ter dito, foi uma atitude estranha.

\footnotetext{
${ }^{1}$ TH respondeu "não sei” por que havia um cartaz com esta opção.
} 
MACEDO - Habilidades cognitivas de um adolescente...

Portanto, como não ficou decidido se TH apresenta problemas ou não nas tarefas de falsa crença de segunda ordem e na tarefa de "faux pas", sugere-se aplicar mais testes que observem em TH esses mesmos aspectos.

\subsection{Memória de Curto Prazo: Tarefa de digit probe-span}

O que se entende pela palavra memória? A memória é o meio pelo qual se recorre às experiências passadas a fim de usar essas informações no presente. Como um processo, a memória refere-se aos mecanismos dinâmicos associados à retenção e à recuperação da informação sobre a experiência passada (CROWDER, 1976). A aprendizagem tende a cobrir o processo de armazenagem, ou seja, a colocação de informações na reserva mnemônica, ao passo que a memória tende a ocupar-se da retenção e recuperação.

Os principais processos de memória abrangem três operações: codificação, armazenamento e recuperação. Cada uma representa um estágio no processamento da memória. A codificação refere-se ao modo pelo qual é transformado o input físico e sensorial é representado na memória. $\mathrm{O}$ armazenamento refere-se à maneira de como a informação é mantida na memória. A recuperação refere-se à maneira de como a informação armazenada é acessada na memória. Codificação, armazenamento e recuperação interagem reciprocamente e são interdependentes.

Muitas das pesquisas sobre memória humana têm sido feitas com pacientes que sofrem de amnésia. Uma das razões pelas quais o estudo de pacientes amnésicos tem sido tão motivador é que ele tem fornecido uma forma diferente de avaliação das teorias sobre a memória normal. A partir de testes, descobre-se que alguns pacientes têm uma memória de longo prazo com graves deficiências, mas uma memória de curto prazo intacta, ao passo que outros pacientes demonstram o padrão oposto, comprovando, assim, a existência de armazenadores de curto e de longo prazo.

Embora a maioria das pessoas tenha pouco ou nenhum acesso introspectivo aos repositórios de memória sensoriais, todas as pessoas têm acesso aos armazenamentos de memória de curto prazo, que mantêm as memórias por alguns segundos e, ocasionalmente, até por alguns minutos. A memória de curto prazo pode ser definida como um mecanismo cognitivo que permite guardar com eficácia um número limitado de informações por um breve período de tempo, segundo Smith, E.E., e Geva, A. (2000). Ou, ainda, Gathercole \& Baddeley (1990) define a memória de curto prazo como a capacidade flexível de armazenar e manipular informações por um breve período de tempo. Isso compreende situações simples de recuperação de material como, por exemplo, lembrar de um número de telefone até que possamos anotá-lo. Segundo o modelo de Atkinson-Shiffrm, o armazenamento de curto prazo, mantém não apenas alguns itens, mas também os processos de controle que regulam o fluxo da informação para o armazenamento de longo prazo e a partir deste, onde se pode manter a informação por um período mais longo.

Quantos itens de informação podem manter na memória de curto prazo? Em um artigo clássico, George Miller (1956) observa que a capacidade de memória de curto prazo para uma ampla série de itens parece ser de aproximadamente sete itens. Ao agrupar uma série de 20 letras ou algarismos em sete itens significativos, pode-se lembrá-los, ao passo 
Cadernos de Estudos Lingüísticos 48(2) - Jul./Dez. 2006

que não se poderia lembrar de 20 itens e repeti-los imediatamente. Por exemplo, a maioria das pessoas não pode manter na memória de curto prazo esta fileira de 21 algarismos: 010010001000010001000. Entretanto, se estes números fossem agrupados em unidades maiores, tais como 01001000100001000 1000, provavelmente, muitas pessoas seriam capazes de reproduzir facilmente os 21 algarismos como seis itens (cf. Miller, 1956, quanto a dígitos binários vs. octais).

Outros fatores, também, influenciam a capacidade de memória para armazenamento temporário. Por exemplo, o número de sílabas pronunciadas tem afetado o número de itens que se pode evocar. Quando cada item tem um maior número de sílabas, pode-se lembrar de menos itens (p. ex., BADDELEY, THOMSON \& LUCHANAN, 1975; CHWEICKERT \& BORUFF 1986; NAVEH-BENJAMIN \& AYRES, 1986;). Além disso, qualquer atraso de interferência pode reduzir a capacidade de memória de sete itens para cerca de três itens.

Outro experimento clássico foi o de Conrad, R., (1964). Conrad apresentou, visualmente aos sujeitos uma série de 6 letras, na velocidade de 0,75 segundos por letra. Após a apresentação da série de letras, os sujeitos deveriam repetir a mesma seqüência. No entanto, apesar das letras terem sido apresentadas visualmente, os erros tendiam a ser baseados na falta de distinção acústica. Desse modo, os sujeitos confundiam, provavelmente, b com $\mathrm{p}, \mathrm{b}$ com $\mathrm{v}$, etc.

Embora o experimento de Conrad mostre a importância de um código acústico, ao invés de um código visual, na memória de curto prazo, há possibilidades de que haja outros códigos. Alan Baddeley (1966) demonstra que a memória de curto prazo conta, também, com o código semântico. No seu experimento, compara o desempenho de sujeitos na evocação de listas de palavras acusticamente confundíveis, por exemplo, cap e map, com uma lista acusticamente diferente, por exemplo, pit - day, e descobre que o desempenho é muito pior para a apresentação visual de palavras acusticamente semelhantes. Em compensação, quando compara o desempenho para a lista de palavras semanticamente similares, tais como big - long, o desempenho para lista de palavras semanticamente diferente, tais como old - hot, demonstra pequena diferença na evocação entre as duas listas. Se o desempenho para palavras semanticamente similares tivesse sido muito pior, indicaria que os sujeitos estavam confusos pela semelhança semântica e, conseqüentemente, estavam processando as palavras semanticamente. Entretanto, o desempenho para palavras semanticamente similares é levemente pior do que aquele para palavras semanticamente diferentes.

Mais tarde, os trabalhos de Harvey Shulman (1970) e de Delos Wickens, Dalezman e Eggemeier, (1976) mostram evidências de algumas codificações semânticas na memória de curto prazo. Além disso, Posner, Boies, Eichelman e Taylor (1969), Posner e Keele, (1967) encontram evidências de que, de forma temporária, também se codifica visualmente a informação.

Se, por um lado, a informação armazenada temporariamente na memória de curto prazo parece ser codificada, basicamente, de forma acústica, embora não exclusivamente, por outro lado, a informação armazenada na memória de longo prazo parece ser, basicamente, codificada semanticamente, ainda que não exclusivamente. 
MACEDO - Habilidades cognitivas de um adolescente...

A corrente mais completa de memória de curto prazo é o modelo de memória de trabalho de Baddeley e Hitch (1974), revisado por Baddeley, em 1986. De acordo com este modelo, a memória de trabalho compreende três componentes: o executivo central, o circuito (loop) fonológico e o esquema viso-espacial. Os dois últimos componentes são caracterizados por Baddeley e Hitch como "sistemas escravos" que são especializados no processamento e manipulação de uma quantidade limitada de informações dentro de grandes domínios específicos. O material é armazenado no circuito fonológico em termos de sons baseados na qualidade fonológica, considerando que o esquema tem uma capacidade de manter propriedades visuais e espaciais de quantidade limitada de informações. Em contraste, para o grande domínio informacional específico onde estes dois sistemas escravos operam, o executivo central é capaz de desempenhar uma série de funções de alto nível. As funções atribuídas ao executivo central incluem: a coordenação da corrente de informações por meio da memória de trabalho, a recuperação de informações para estocagem da memória de longo prazo mais permanente, a aplicação de estratégias de recuperação, raciocínio lógico e aritmética mental.

Diversas teorias foram propostas quanto ao motivo do esquecimento de uma informação armazenada na memória de curto prazo. Citam-se duas teorias: a da interferência e da degradação. A interferência ocorre, quando informações competidoras levam-nos a esquecer alguma coisa, distinguem-se entre a interferência retroativa e a interferência proativa. Já a degradação ocorre quando, com o tempo, esquecemos uma informação.

A transferência da informação para o armazenamento de longo prazo pode ser facilitada pela repetição da informação, pela organização da informação (por ex. categorização), pelo uso de estratégias mnemônicas e pelo uso de auxílio externo para a memória (tomar nota). Além disso, há a tendência para se lembrar melhor quando o conhecimento é adquirido pela prática distribuída ao longo de várias sessões e não numa única sessão mesmo que ela tenha um tempo maior do que o tempo das várias sessões.

É complexo estudar a recuperação da memória. A memória parece ser tanto reconstrutiva, baseada no que foi aprendido, quanto construtiva, influenciada por informações adquiridas ulteriormente e por esquemas baseados no conhecimento anterior. Logo, os contextos internos e externos afetam o que lembramos.

\subsubsection{Experimento 5: Memória de Curto Prazo - Tarefa de Digit Probe-Span}

Para a apresentação deste teste aos sujeitos foi utilizado um gravador Sony- Portable MiniDisc Recorder, Walkman TM, MZ - R30, 1996, com dois fones de ouvido.

Os estímulos são constituídos de dígitos que foram gravados no Laboratório de Fonética Acústica da Universidade Federal de Santa Catarina - UFSC-, no programa chamado CSL. Este material foi construído por Rosilane Mary dos Passos para o seu trabalho "Memória imediata em crianças e adultos com diferentes graus de escolaridade".

As gravações foram realizadas no mês de outubro de 1999. Foram realizadas pelo menos três (3) gravações de cada conjunto de estímulos os quais foram escolhidos posteriormente de acordo com a entonação, ritmo e compasso, de modo que as finalizações não servissem como índice de recordação aos sujeitos. 
No teste de memória a curto-prazo - digit probe-span - o sujeito ouviu primeiro uma sequiência de itens (dígitos de 1 a 5) e , a seguir, o pesquisador dizia, em voz alta, um desses itens. A tarefa dos sujeitos era a de dizer aquele item que ouviu imediatamente após o item dito pelo pesquisador.

Para a resposta de TH foram apresentados 5 cartões $(15 \mathrm{~cm} \mathrm{x} 15 \mathrm{~cm})$, cada um contendo um dígito de 1 a 5, dispostos a sua frente em forma de X, ou seja, lado direito em cima (1), lado direito em baixo (2), centro (3), lado esquerdo em cima (4), lado esquerdo em baixo(5) - o olhar firme de TH para um dado cartão significava - resposta correta.

$\mathrm{O}$ teste começou numa seqüência de quatro itens. Com quatro acertos sobre sete passavam adiante, para seqüência mais longa, ou seja, para uma seqüência de cinco itens. Se o indivíduo não acertasse quatro seqüências em sete, dever-se-ia passar para uma sequiência menos longa, isto é, para uma seqüência de três itens.

Houve uma fase de treino em que as respostas eram aprovadas ou corrigidas verbalmente. Somente, após a compreensão da tarefa que se passou para os testes.

\subsubsection{Resultados do experimento 5}

Os resultados da tabela abaixo demonstraram que, numa seqüência de no máximo seis dígitos, o grupo controle - colegas de sala de aula de TH - obteve um span médio de 5,37 e um desvio padrão de 1,55. Por sua vez, TH obteve um span de 4,43.

Gráfico 2: Distribuição da pontuação dos sujeitos.

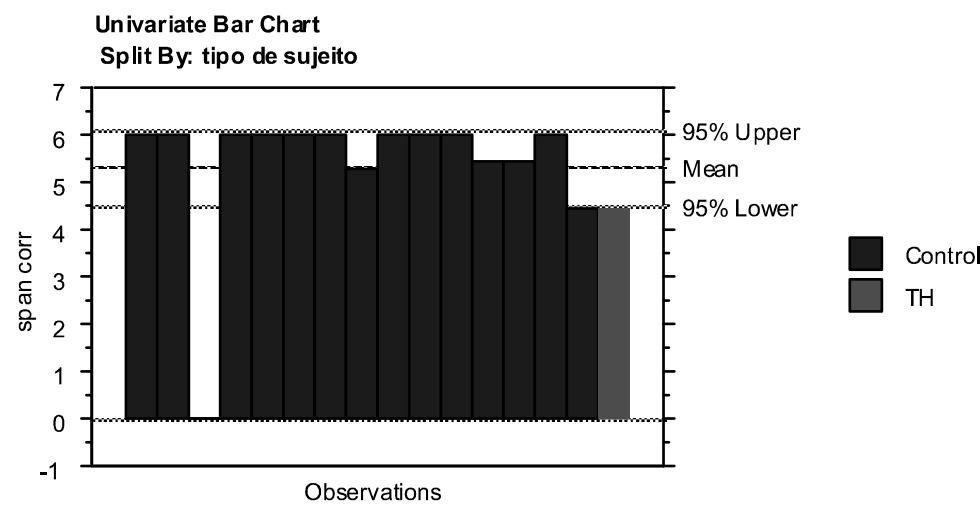

No gráfico 2, é importante notar que a média do grupo controle teve uma forte queda pelo fato de um único sujeito, que parece não ter compreendido nada da tarefa, não ter respondido corretamente as questões. Por conseqüência, para o grupo controle, a média e a variação foram calculados sem o sujeito incomum no grupo. A média do grupo controle foi de 5.76 (desvio padrão 0,46 ). 
MACEDO - Habilidades cognitivas de um adolescente...

A partir do gráfico, percebe-se claramente que um sujeito do grupo controle apresenta o escore (mínimo) de 4,43, idêntico ao escore de TH, 4,43. Apesar do sujeito controle apresentar o pior escore do grupo, ele está no limite da normalidade. Portanto, TH apresenta um desempenho normal frente ao grupo controle.

\subsection{Teste de Palmer - Tarefa Part-Probe}

No início do século passado, uma das importantes áreas de investigação psicológica foi a de percepção de figuras geométricas. Esta investigação tinha o objetivo de determinar se as leis básicas da percepção descritas pelos psicólogos da Gestalt eram as mesmas para sujeitos originados em diferentes sistemas sócio-econômicos.

Uma das tarefas que tem sido utilizada mais recentemente no estudo de percepção visual é a tarefa que Palmer (1977) chama de part-probe - sondagem de partes. Esta tarefa, também, é utilizada neste estudo.

A idéia básica da tarefa de sondagem de partes é de que a representação perceptual de um objeto complexo pode ser estruturada hierarquicamente (REED, 1973; SUTHERLAND, 1968), sendo assim, a representação perceptual é formada por numerosos níveis de representação em forma de rede. Segundo Palmer (1977), em cada nível da hierarquia, as unidades estruturais são definidas tanto como um conjunto de propriedades globais quanto um conjunto organizado de partes. Um dos aspectos importantes deste teste está na hipótese de organização seletiva, ou seja, nem todos os subconjuntos de elementos de uma figura são codificados como uma unidade estrutural.

Palmer desenvolveu uma função algébrica para especificar as relação entre os segmentos de figuras de linha complexa. Desta maneira, ele pode definir três níveis de encaixe de partes formadas de três segmentos na figura geométrica composta de seis segmentos, a primeira figura da esquerda para a direita é a própria figura geométrica, a segunda é de partes salientes, a terceira é de partes medianamente camufladas, a quarta parte de figuras muito camufladas e a quinta e a sexta figura são de partes que não correspondem a figura geométrica como está ilustrado na figura 2, níveis definidos em função de suas relações entre segmentos e com os segmentos do resto da figura. Na tarefa de sondagem de partes, aos sujeitos foram pedidos para decidir se uma parte de três segmentos figura fazia parte ou não da figura de seis segmentos apresentada. Os resultados mostraram que as respostas positivas corretas foram mais rápidas para as partes mais salientes do que para partes muito ou mediamente camufladas na figura.

Figura 2: Teste de cognição visual.

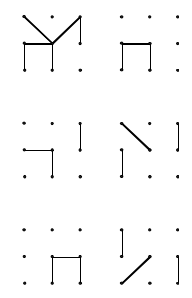


Cadernos de Estudos Lingüísticos 48(2) - Jul./Dez. 2006

Anos depois, dois estudos experimentais realizados por Kolinsky, Morais, Content e Cary (1987) e por Kolinsky, Mendes, B.C., \& Morais (1990) utilizaram a tarefa de sondagem de partes designada por Palmer (1977) com crianças pré-escolares, crianças de escola primária e iletrados. Nos dois estudos este tipo de material com adultos não escolarizados, mesmo que eles tenham permanecido analfabetos ou não, Kolinsky et al. (1987; 1990) mostraram que estes detectam com mais facilidade uma parte camuflada em uma figura, mesmo se dispõem de um tempo ilimitado para realizar a tarefa. Desta maneira, os adultos não escolarizados detectam, somente, em torno de $25 \%$ das partes camufladas, enquanto as crianças do segundo ano primário detectam essas mesmas partes em cerca de $75 \%$ dos casos. Essa dificuldade não pode ser explicada por razão de uma má compreensão da tarefa, uma vez que essa dificuldade não se manifesta quando a parte, para ser detectada, é pouco camuflada. Além do mais, é de fazer notar que um procedimento de reforço e correção de respostas, aplicado aos adultos não-escolarizados (MENDES, B.C., KOLINSKY \& MORAIS, 1988) não chegou a melhorar suas performances. Portanto, esses resultados sugeriram que os processos de análise pós-perceptual necessários para encontrar uma parte de um figura dependem da instrução ou da experiência vinda da escola.

No entanto, tais processos não devem ser confundidos com aqueles que levam a formar a percepção. Pois, o estudo das capacidades de análise visual perceptiva de adultos não escolarizados, realizada através do exame de padrões de erros de percepção, mostrou que a representação separada dos componentes dos objetos é semelhante, no nível perceptivo, tanto nos adultos não alfabetizados quanto nos adultos escolarizados (KOLINSKY, MORAIS \& VERHAEGHE, 1994).

$\mathrm{Na}$ teoria cognitiva é importante distinguir entre percepção e pós-percepção ou processamento cognitiva da informação visual (KOLINSKY, 1996; 1999; KOLINSKY \& MORAIS, 1999; PYLYSHYN, 1999). Pode-se chamar de processos perceptuais aqueles que levam de maneira não intencional para uma representação consciente de algum estímulo e processos pós-perceptuais ou cognitivo aqueles que operam em tais representações e tanto podem quanto não podem ser empregados, dependendo do objetivo. Os dados de Kolinsky e colaboradores mostram que é só para os processos cognitivos, pós-perceptuais, que se observa um efeito da escolarização.

Mais, a escolarização poderia não ser o único fator que afetaria as capacidades de análise visual. Segundo a hipótese de Luria (1976), uma pessoa cuja atividade diária é caracterizada, principalmente, por condições concretas, gráfico-funcionais e pela prática, obviamente, distinguirá e perceberá aspectos geométricos diferentemente de uma outra pessoa que pode basear-se no treino teórico e em um sistema de conceitos geométricos bastante diferenciados.

\subsubsection{Experimento 6: Teste de Palmer - Tarefa part-probe}

O estímulo deste teste é o sub-conjunto da tarefa sondagem de partes de Palmer utilizado por Kolinsky et al. (1987). Como naquele estudo, usam-se três classificações de relações entre partes e figura: partes salientes, partes muito camufladas e partes mediamente camufladas na figura. 
Ao contrário do que foi feito nos estudos anteriores, o teste foi apresentado a TH da seguinte maneira: todos os pares de uma mesma figura foram apresentados ao mesmo tempo. Ou seja: cada uma das cinco figuras de seis segmentos foi apresentada com cinco figuras compostas de três segmentos. Para cada uma figura de seis segmentos foi apresentado três pares positivos, um para cada nível de relação entre parte e figura, e dois pares negativos. Nos pares negativos, pelo menos um segmento não compartilhava com a figura. Há um total de quinze pares positivos e dez pares negativos.

Cada estímulo, uma matriz $3 \times 3$, foi feito no centro de um cartão branco com tinta preta. A matriz media $2 \mathrm{~cm}$ de altura por $2 \mathrm{~cm}$ de largura. Cartões separados são usados para cada figura e seus pares. Os cartões são dispostos na frente de TH em forma de X, ou seja, lado direito em cima, lado direito em baixo, centro, lado esquerdo em cima, lado esquerdo em baixo - o olhar firme de TH para um dado cartão significava - resposta escolhida.

Como exemplo, uma figura de seis segmentos foi apresentada com cinco figuras compostas de três segmentos (três pares positivos e dois pares negativos) a TH. Primeiramente, foram apresentados dois pares positivos e um negativo e, em seguida, foi apresentada a tarefa completa. Durante a fase de treino, as respostas foram aprovadas ou corrigidas verbalmente. Somente, após a compreensão da tarefa que se passou para os testes.

\subsubsection{Resultados do experimento 6}

A tabela 2 mostra a porcentagem de respostas positivas corretas: partes salientes, partes muito camufladas e partes mediamente camufladas na figura.

Como se pode verificar na tabela apresentada abaixo, tanto a performance para os pares salientes quanto para os pares negativos mostram que o TH percebeu bem a tarefa. Pois, ele obteve 80 de respostas corretas para os pares de partes salientes e $90 \%$ das respostas corretas para pares negativos. Mas, quando a tarefa é cognitivamente exigente, como para os pares partes muito camufladas e partes mediamente camufladas, TH é incapaz de encontrar a parte na figura: ele obtém somente $20 \%$ de respostas corretas nos dois casos. Portanto, os resultados indicam que TH apresenta problemas sérios de cognição visual.

Tabela 2: Porcentagem de respostas na tarefa part-probe.

\begin{tabular}{|c|c|c|c|c|}
\cline { 2 - 5 } \multicolumn{1}{c|}{} & \multicolumn{3}{c|}{ Pares Positivos } & Pares Negativos \\
\hline $\begin{array}{c}\text { Tipo de par } \\
\text { positivo }\end{array}$ & salientes & $\begin{array}{c}\text { Medianamente } \\
\text { camuflado }\end{array}$ & $\begin{array}{c}\text { Muito } \\
\text { camuflado }\end{array}$ \\
\hline$\%$ correto & $80 \%$ & $20 \%$ & $20 \%$ & $90 \%$ \\
\hline
\end{tabular}


Cadernos de Estudos Lingüísticos 48(2) - Jul./Dez. 2006

Apesar do fato de TH ser escolarizado, e apesar do fato de que os procedimentos tenham sido ligeiramente diferentes, ele obteve resultados extremamente similares àqueles dos adultos não escolarizados estudados por Kolinsky et al. (1987).

\section{DISCUSSÃO FINAL}

A investigação sobre o funcionamento cognitivo de TH, sujeito com lesão cerebral e comprometimento na fala, revela que ele emparelha com o grupo controle em alguns aspectos do seu desempenho cognitivo.

O teste de inteligência geral - matriz de Raven (1938) indicou que TH apresenta problemas para representar um material gráfico. Esses problemas podem ser de raciocínio analítico, ou de percepção ou de cognição visual. O teste de matriz de Raven foi aplicado com êxito por (BADDELEY \& WILSON, 1985; BISHOP \& ROBSON, 1989; SANDBERG, D.A., \& HJEIMQUIST, 1997) em grupos de indivíduos não falantes. Uma das facilidades deste material é o emprego de figuras geométricas que não implicando a manipulação de material concreto nem interpretação de imagens (representação de objetos ou de cenas).

O teste de categorização - teste de emparelhamento espontâneo de imagens, sugeriu que TH não difere do grupo controle. Este achado é reforçado pelos resultados de vários outros estudos, entre eles, Smiley e Brown (1977) afirmam que as crianças de 5 anos de idade poderiam combinar itens em bases de relações taxonômicas, no entanto, elas preferem usar relações funcionais e perceptuais. Morais e Kolinsky (1999), também, confirmaram a inclinação demonstrada por Luria (1976) de que sujeitos iletrados e ex-iletrados emparelham itens mais sobre bases de relações funcionais do que taxonômicas. Além disso, pesquisas recentes mostram que adultos utilizam, preferencialmente, relações esquemáticas funcionais e taxonômicas (ROSS \& MURPHY, 1999; VALLÉE-TOURANGEAU, ANTHONY \& AUSTIN, 1998). Assim, a coexistência das representações esquemáticas e taxonômicas, demonstradas desde a idade de um ano, perduram até a idade adulta. Segundo Blaye, Bernard-Peyron \& Bonthoux (1989), os modos de categorização variam conforme os contextos e as características individuais.

O teste de raciocínio - tarefa de seleção de Wason (1966) sugere que TH se encontra dentro da normalidade frente ao grupo controle. A partir dos testes, ficou sugerido que os sujeitos compreenderam a tarefa. Ou seja, eles compreenderam através da questão "Você acha que isto que estou dizendo está certo ou está errado?" que a regra deveria ser ou não ser confirmada, mas as reclamações de todos os sujeitos controles demonstraram que eles não entendiam suas próprias opções. Wason \& Evans (1975) indicam que a escolha dos cartões são mediadas por processos inconscientes. Mesmo assim, a tarefa provoca o pensamento analítico. Evans (1975) afirma que os sujeitos pensam no problema, focalizando seletivamente e, portanto, observando as características mais relevantes do problema e não todas as características. É importante mencionar que essa tarefa apresenta um número bastante pequeno de acertos (JOHNSON-LAIRD E WASON, 1970).

O teste de teoria da mente - tarefa de falsa crença de primeira e segunda ordem e a "faux pas" - não pode confirmar se TH apresenta ou não problemas na "teoria da mente", 
MACEDO - Habilidades cognitivas de um adolescente...

ou seja, segundo Stone, Baron-Cohen \& Knight (1998), não ficou demonstrado se TH apresenta ou não a habilidade de fazer inferências sobre os estados mentais de outros. Baron-Cohen et al. (1997) sugeriu a partir dos testes de detenção de "faux pas", que, como crianças de 7 e 8 anos de idade, indivíduos com síndrome de Asperger - uma forma moderada de autismo-, poderiam passar nas tarefas de falsa crença de primeira e segunda ordem, porém, seriam prejudicados na tarefa de "faux pás". Logo, a tarefa de "faux pas" é uma boa medida da teoria de déficits mentais sutis como, por exemplo, reconhecer um lapso social (STONE, BARON-COHEN, KNIGHT, 1998). A partir dos resultados, ficou impossível afirmar que se trata do mesmo caso de TH. Por essa razão, sugere-se outros testes que avaliem, em TH, a atribuição de crenças e inferências sobre o estado mental de outras pessoas.

O teste de memória de curto prazo - tarefa de dígito de sondagem escopo demonstra que TH apresenta um desempenho normal frente ao grupo controle. Burtis (1982) sugere que existe uma correlação entre o span de memória de curto prazo e a capacidade mental. Experimentos de neuroimagem sustentam a afirmação de que a memória de trabalho verbal consiste de um processo de repetição e de um processo de estocagem. Estes estudos indicam que o processo de repetição é implementado por mecanismos envolvendo a fala. Assim, a memória verbal depende da linguagem ou pelo menos da linguagem fonológica (SMITH, E.E., \& GEVA, A., 2000). Estes resultados são interessantes uma vez que TH não apresenta fala produtiva mas, mesmo assim, tem as habilidades de leitura e escrita.

O teste de cognição visual de Palmer (1977) indica que TH apresenta problemas sérios de cognição visual. Os resultados do teste sugere que TH tem dificuldades para perceber figuras geométricas complexas. Além disso, os resultados indicam que TH apresenta dificuldade para observar um conjunto de propriedades e depois desmembrá-lo e o contrário também pode ser sugerido, ou seja, observar várias partes de uma figura e depois agrupá-la. Essas dificuldades poderiam ser explicadas pelos estudos de Kolinsky, Morais, Content e Cary (1987) e por Kolinsky, Brito Mendes \& Morais (1990) que utilizaram a tarefa de sondagem de partes designada por Palmer (1977) com crianças pré-escolares, crianças de escola primária e iletrados. Esse trabalho sugeriu que os processos de análise pós-perceptual necessários para encontrar uma parte de um figura dependem da instrução ou da experiência vinda da escola. No caso específico de TH, hipotetiza-se que, somente a escolarização não foi suficiente para aguçar o raciocínio analítico, a percepção e a cognição visual de material gráfico, mas seria necessárias experiências práticas - o que para ele é impossível em função do seu dano motor.

Portanto, a partir dos resultados fica sugerido a aplicação de teste que demonstre a capacidade de TH para inferir os estados mentais de outras pessoas mas, principalmente, testes de cognição visual, porque foram nestes testes que TH demonstrou ter dificuldades para resolver as tarefas.

\section{REFERÊNCIAS BIBLIOGRÁFICAS}

ASTINGTON, J.W., \& JENKINS, M.J. (1999). A Longitudinal study of relation beetween language and theoryof-mind development. Language and Theorry of Mind. University of Toronto. 
BADDELEY A., \& WILSON, B. (1985). Phonological coding and short-term memory in patients without speech. Journal of Memory and Language, 24: 490-502.

BERNINGER, V., \& GANS, B.M. (1986a). Language profiles in nonspeaking individuals of normal intelligence with severe cerebral palsy. Augmentative and Alternative Communication, 2: 45-50.

BISHOP, D.V.M., \& ADAMS, C. (1990). A prospective study of de relationship between specific language impairment, phonological disorders and readind retardation. Journal of Child Psychology and Psychiatry, 31: $1027-1050$.

BISHOP, D.V.M., \& ROBSON, J. (1989). Accurate non-word spelling despite congenital inability to speak: phoneme-grapheme conversion does not require subvocal articulation. British Journal of Psychology, 80: $1027-1050$.

BISHOP, D.V.M., BYERS BROWN, B., \& ROBSON, J. (1990). The relationhip between phoneme discrimination, speech production and language comprehension in cerebral-palsied individuals. Jounal of Speech and Hearing Research, 33: $210-219$.

BLEWITT, P., \& TOPPINO. T.C. (1991). The developmental of taxonomic structure in lexical memory. Journal of Experimental Child Psychology, 51, 296-319.

EDEBOL-TYSK. (1989). Spastic Tetraplegic Cerebral Palsy, epidemiology and Care Load. Doctoral thesis. Göteborg University: Department of Paediatrics II.

FOLEY, B.E. (1993). The development of literacy in individuals with severe congenital speech and motor impairments. Topics in Language Disorders, 13: 16- 32.

GATHERCOLE, S.E., \& BADDELEY, A.D. (1990). Phonological memory deficits in language disordered children: Is there a causual connection? Journal of memory and language, 29: $336-360$.

INHELDER, R., \& PIAGET, J. (1964). Early growth of logic in the child. New York: Norton.

KELFORD SMITH, A., THURSTON,S., LIGHT,J., PARNES,P., \& O'KEEFE, B. (1989). The form and use of written communication produced by nonspeaking physically disabled individual using microcomputers. Augmentative and Alternative Communication, 5: 115 - 124.

KOLINSKY, R. \& MORAIS, J. (1999). We all are Rembrandt experts - or how task dissociations in school learning effects support the discontinuity hypothesis. Behavioral \& Brain Sciences, 22, 381-382.

KOLINSKY, R. (1996). Conséquences cognitives de l'illettrisme. In S. Carbonnel, P. Gillet, M.D. Martory \& S. Valdois (Eds.), Dyslexies et dysorthographies acquises et développementales. Marseille: Ed. Solal, 291304.

. (1999). Literacy and schooling: an often neglected but necessary distinction. In L. Grimm Cabral \& J. Morais (Org.): Investigando a Linguagem. Ensaios em homenagem a Leonor Scliar-Cabral (pp. 297310) Florianópolis: Ed. Mulheres.

KOLINSKY, R., MORAIS, J., \& MENDES, C.B. (1990). Embeddedness effects on part verification in children and unschooled adults. Psychologica Belgica, 30, 49-64.

KOLINSKY, R., MORAIS, J., \& VERHAEGHE, A. (1994). Visual separability: a study on unschooled adults, Perception, 23, 471-486.

KOLINSKY, R., MORAIS, J., CONTENT, A. \& CARY, L. (1897). Finding parts within figures: a developmental study. Perception, 16, 399-407. 
MACEDO - Habilidades cognitivas de um adolescente...

MCGINNIS, J.S., \& BEUKELMAN, D.R. (1989). Vocabulary requirements for writing activities for the academically mainstream stdent with disabilities. Augmentative and Alternative Communication, 5: 183-191.

MENDES, C.B, KOLINSKY, R., \& MORAIS, J. (1988). Spécificité de l'analyse post-perceptive de figures géométriques. In: Conduites et représentations (pp. 197-199). Toulouse: Privat.

MORAIS, J. ALEGRÍA, J., \& CONTENT, A. (1987). The relationship between segmental analysis and alphabetic literacy: Na interactive view. Cahiers de Psychologie Cognitive, 7: 415-438.

MORAIS, J. (1994). Reasons to pursue the study of phonological awareness. Readind and Writing: An Interdisciplinary Jounal, 6: 219-220.

MORAIS, J., \& ROBILLARD, G. (orgs). (1998). Apprendre à lire - au cycle des apprentissages fondamentaux Analyses, réflexions et propositions. Editions Éditions Odile Jacob.

MORAIS, J., MOUSTY, P., \& KOLINSKY, R. (1998). Why and how phoneme awareness helps learning to read. In: Hulme, C. \& Joshi, R. M. Reading and spelling: development and disorders. Mahwah, N. J., Lawrence Erlbaum, 127-151.

MOSS, H. E., OSTRIN, R., TYLER, L. K., MARSLEN-WILSON, W.D. (1977). Accessing different types of lexical semantic information: Evidence from priming. Journal of Experimental Psychology: Learning, Memory e Cognition 21, 863-883.

ROSS, B.H. \& MURPHY, G.L. (1999). Food for thought: Cross-classification and category organization in a complex rea-word domain. Cognitive Psychology, 38, 495-553.

SANDBERG, A.D., \& HJELMQUIST, E. (1997). Language and literacy in nonvocal children with cerebral palsy. Interdisciplinary Jounal, 9: 107-133.

. (1996). Phonological awareness and literacy abilities in nonspeaking preschool chidren with cerebral palsy. Augmentative and Alternative Communication, 12: 138-153.

. (1996). A comparative, descriptive study of readind and writing skills among nonspeaking chidren. A preliminary study. European Journal of disrders of Communication, 31: 289-308.

SCLIAR-CABRAL, L. (1999). Effects of literacy on metalinguistic awareness, Cahiers d'aquisition \& pathologie du langage.

SMITH, M.M. (1989). Reading without speech: a study of children with cerebral palsy. The Irish Journal of Psychology, 10: 601-614.

SMITH, E.E., \& GEVA, A. (2000). Verbal Working memory and its connections to language processing. In Y. Grodzinsk, L.P., Shapin \& D. winney (Eds), Language and the brain. Sain Diego: Academic Press, 123141.

SNODGRASS, J.G., \& VANDERWART, M.A. (1980). A standardised set op 260 pictures: norms for name agreement, familiarity and visual complexity. Journal of Experimental Psychology: General, 6, 174-215.

STONE, V.E., BARON-COHEN, S., \& KNIGHT, R.T. (1998). Frontal Lobe Contributions to Theory of Mind. Journal of Cognitive Neurosciene, 10, 640-656.

VALLÉE-TOURANGEAU, F. ANTHONY, S.H. \& AUSTIN, N.G. (1998). Strategies for generating multiple instances of common and hoc categories. Memory, 6, 555-592.

VERHAEGHE, A. (1999). L'influence de la scolarisation et de l'alphabétisation sur les capacités de traitement visuel. 